\title{
Trend analysis of flood data in Australia: A case study for Victoria
}

\author{
M. S. Hossain, A. Rahman, K. Haddad and E. H. Ishak \\ School of Computing, Engineering \& Mathematics, University of Western Sydney, New South Wales \\ Email: mohammed.hossain@uws.edu.au
}

\begin{abstract}
The possible impact of climate change on water resources management has received a great deal of attention from scientists all over the world. It has been noted that climate change will have a significant impact on various aspects of hydrologic cycle such as rainfall and floods. Due to climate change, the flood data can no longer be assumed stationary. Previous studies have shown that about $15 \%$ of Australian stream gauging stations show trends in annual maximum flood data, mostly downward in the south \& south-east regions and upward in the northern region. These studies were based on the flood data till 2005 as part of Australian Rainfall and Runoff Revision Project 5. In this study, an updated database has been prepared for the annual maximum floods covering till year 2011 for the state of Victoria. This updated database is then used in this paper to identify trends in annual maximum flood series data using Mann-Kendall test. It has been found that $26 \%$ of the selected stations exhibit a downward trend at $5 \%$ level of significance, and none show an upward trend.

The trend analysis was also repeated for $10 \%$ and $1 \%$ significance levels as well. Here, 60 stations show trends (i.e. $39 \%$ of the stations) at $10 \%$ level of significance and 14 stations show trends (i.e. $9 \%$ of the stations) at $1 \%$ level of significance. In all cases, the demonstrated trends are much higher than that would have been shown by mere sampling variability. Furthermore, no noticeable relationship between trends and catchment areas is identified. The reason behind these trends is being examined, and will be reported in future publications.
\end{abstract}

Keywords: Trend, Australian Rainfall and Runoff, annual maximum flood series, non-parametric test, floods. 


\section{INTRODUCTION}

Climate change due to possible anthropogenic greenhouse gas emission to the atmosphere and natural climate variability are obvious sources of the temporal variations in hydrological and flood series data. Recent research outcomes show a changing rainfall regime over most parts of the Australian continent (Power et al., 2005) and particularly, south-east Australia is experiencing a long-term dry spell similar to south west of Western Australia that began in 1970s. Murphy and Timbal (2008) stated that drought is a recurring problem in south-eastern Australia i.e. it expects more wet years to compensate for drought and many water resources systems have been designed to cope with this situation. Drought spell for a long period of time creates the problem with the linear relationship between rainfall and runoff e.g. a higher rainfall over a significant period is needed to saturate the dry soil before a small amount of runoff can be generated.

Many studies have found a downward rainfall trend in south-east Australia. For example, Stern et al. (2005) found a downward trend in annual mean rainfall in Melbourne. Murphy and Timbal (2008) suggested that Australia, in particular the southeast region have been receiving rainfall in many years that is generally lower than the average. It is important to note that Australian mean temperature has accelerated in the last couple of decades, more than double as compared to previous decades. The warming affects the droughts in large scale as it means higher temperatures and, therefore, more evaporation. Nicholls (2003) stated negative correlation between mean annual Australian rainfall and maximum temperature, so that low rainfall years correspond to those with average temperature.

Whetten (1988) showed that different pressure pattern on the sea-surface are the main contributor of the variation of rainfall in Victorian region. Murphy and Timbal (2008) stated that the hydro-metrological cycles of south-east Australia are influenced on intra-seasonal and longer time scales by many of the major index of natural climate variability where the most extensive one is El Nino Southern Oscillation (ENSO). The natural variability occurs over a number of timescales, from annual through to multi-decadal. ENSO, Inter-decadal Pacific Oscillation (IPO) and Southern Annular Mode (SAM) are well-known natural climate variability indices that affect Australian climate (Hendon et al., 2007). The association between ENSO events and Australian climate is modulated by IPO as noted by Power et al. (1999).

A vast number of studies have been undertaken worldwide to investigate the existence of trends in streamflow data. These studies have adopted a variety of tests such as non-parametric, parametric, Bayesian, time series and resampling approaches to identify the trends in hydrological time series data. In Australia, many researchers studied trends to identify the effects of climate change and climate variability on streamflow data. Many studies focus the decreasing trends of Australia's streamflow data in the southern parts of Australia. For example, Whetten (1988) stated that the sea pressure anomalies are the main cause for the rainfall variability in Victoria as different pressure pattern brings rain to each of the five rainfall regions of Victoria following mechanisms that effect south east Australian climate variability by bringing precipitation to the region and affecting the atmospheric temperature that is easily identified as circulation anomalies. Murphy and Timbal (2008) noted that south-eastern region of Australia had been experiencing an annual rainfall downward trend at the rate of $20.6 \mathrm{~mm}$ per decade since 1950.

Haddad et al. (2008) studied trends in the annual maximum flood series data till 2005 and identified a decreasing trend in many Victorian stations. Ishak et al. (2010) investigated trends in the annual maximum flood data using 491 Australian stations using non-parametric tests. They found a significant trend, generally downward to the south-east and south-west Australian regions, and an upward trend in the northern region. They found that $21 \%$ to $30 \%$ of stations showing a downward trends and only $1 \%-6 \%$ of stations showing an upward trend. The studies by Haddad et al. (2008) and Ishak et al. (2010, 2013) used annual maximum flood series data up to 2005. This paper examines the trends in annual maximum flood data till 2011 for the state of Victoria.

\section{METHOD}

The target of this study is to determine if any trend exists in the annual maximum flood series data in the state of Victoria. There are two types of trend test that are generally adopted for identification of trends: Parametric and non-parametric tests. Mann-Kendall, Spearman's Rho and Sen's slope estimator are nonparametric while Least Squares Linear Regression, Student's $t$ are parametric tests. For parametric test, data of the series of observation must be independent and normally distributed but non-parametric tests are distribution free and could accept outliers in the data series. Though non-parametric trend tests are generally considered to be less powerful than parametric tests, it is widely used for detecting trends in hydrological time series, as most of this data are not normally distributed. 
Mann-Kendall test: It is a rank-based test for determining monotonic trends in time series data (Mann, 1945; Kendall, 1975; Helsel and Hirsh, 2002). The Mann-Kendall test accounts for a trend in a hydrologic time series without specifying whether the trend is linear or non-linear (Khaliq et al., 2009). The MannKendall test statistics " $S_{0}$ " is calculated using the following equation:

$$
\left.\begin{array}{c}
S_{0}=\sum_{i=1}^{n-1} \sum_{j=i+1}^{n} \operatorname{sgn}\left(\Theta_{j}-\Theta_{i}\right) \\
\operatorname{sgn}(R)=1 \text { for } R>0 \\
\operatorname{sgn}(R)=0 \text { for } R=0 \\
\operatorname{sgn}(R)=-1 \text { for } R<0
\end{array}\right\}
$$

Where $\Theta_{i}$ and $\Theta_{j}$ are the sequence of the data, $n$ denotes the total number of data points in the series.

For $n \geq 8$, it is assumed that statistic $S_{0}$ is normally distributed (Mann, 1945 and Kendall, 1975) where the mean and variance of $S_{0}$ are described as follows:

$$
\eta\left[S_{0}\right]=0 \text { and } \operatorname{var}\left(S_{0}\right)=\left[n(n-1)(2 n+5)-\sum_{i=1}^{N} t_{i} i(i-1)(2 i+5)\right] / 18=\sigma^{2}
$$

Where $t_{i}$ is the number of data in the tied group and $N$ is the total number of tied groups. The standard test statistic $Z_{0}$ is obtained as:

$$
Z_{0}= \begin{cases}\frac{S_{0}-1}{\sigma} & \text { if } S_{0}>0 \\ 0 & \text { if } S_{0}=0 \\ \frac{S_{0}+1}{\sigma} & \text { if } S_{0}<0\end{cases}
$$

The existence of statistically significant trend is calculated using the $Z_{0}$ value. The upward and downward trends are identified with the positive and negative values of $Z_{0}$ respectively. To test for monotonic trend, at $\alpha$ level of significance, either an upward or downward, for two-tailed test, null hypothesis, $H_{0}$ should be rejected if the $\left|Z_{0}\right|>Z_{0}{ }_{1-\alpha / 2}$ is determined from the standard normal cumulative distribution tables. For instance, at the 95\% confidence level $H_{0}$ should be rejected, if $-1.96 \times Z \times+1.96$. The trend is more statistically significant if the magnitude of $Z_{0}$ value become bigger.

\section{STUDY AREA AND DATA}

A total of 152 catchments from Victoria are selected in this study to investigate the trends in the annual maximum flood data. The geographical distribution of these stations is shown in Figure 1. It is found that there is good spatial distribution of stations over the entire state except the northwest Victoria. This is due to the absence of good quality streamflow stations with longer record lengths in this part of Victoria.

The annual maximum flood database in this paper has been taken from the current revision of the regional flood estimation method in Australian Rainfall and Runoff Project 5 (Rahman et al., 2012). The selected stations contain annual maximum flood data of minimum and maximum record lengths of 26 years and 58 years, respectively, with an average of 33 years. 
The distribution of the record lengths of the 152 stations is shown in Figure 2. From this figure, it can be found that most of the streamflow stations contain record lengths between 36 years to 40 years and the distribution of record lengths of the stations of the 39 catchments that are showing trend at $5 \%$ level of significance is represented in Figure 3. The catchments areas of the selected catchment stations fall between $3 \mathrm{~km}^{2}$ and $997 \mathrm{~km}^{2}$, with an average value of $261 \mathrm{~km}^{2}$. The distribution of catchment areas is shown in Figure 4 , where it is found that most of the stations are smaller than $500 \mathrm{~km}^{2}$. Figure 5 shows distribution of catchment areas of the 39 stations that are showing trends at $5 \%$ level of significance.

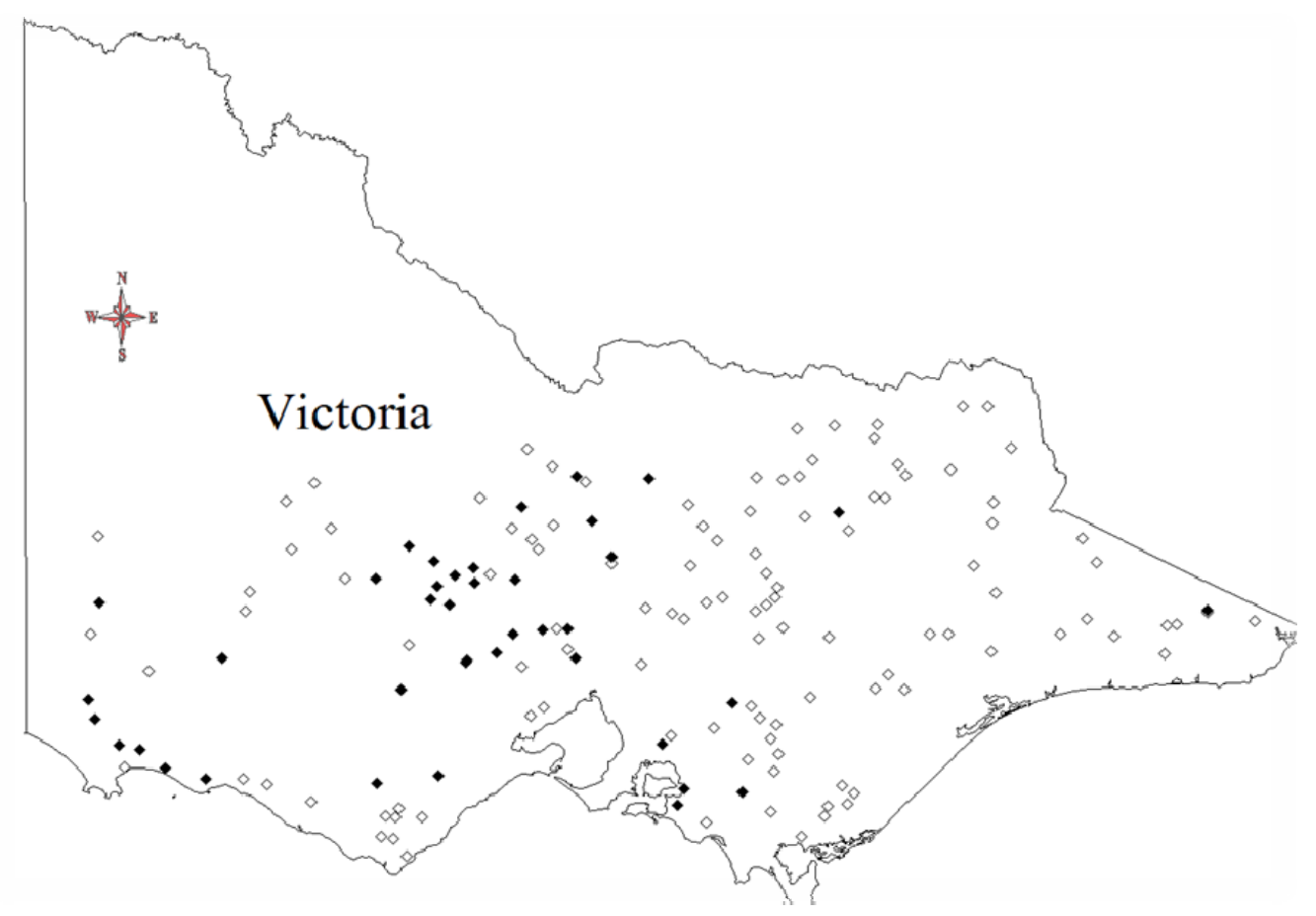

Figure 1. Locations of 152 study catchments from Victoria. Dark squares indicate stations showing trend.

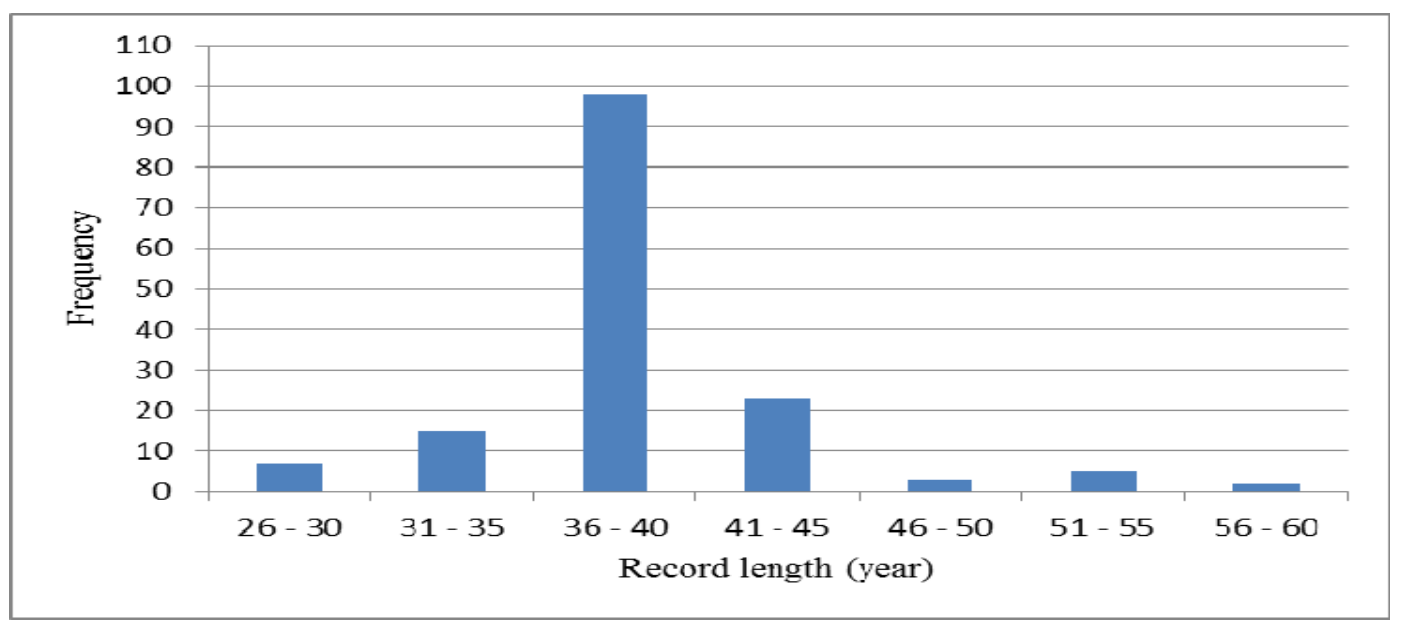

Figure 2. Distribution of record length of the annual maximum flood data of all the 152 catchments. 


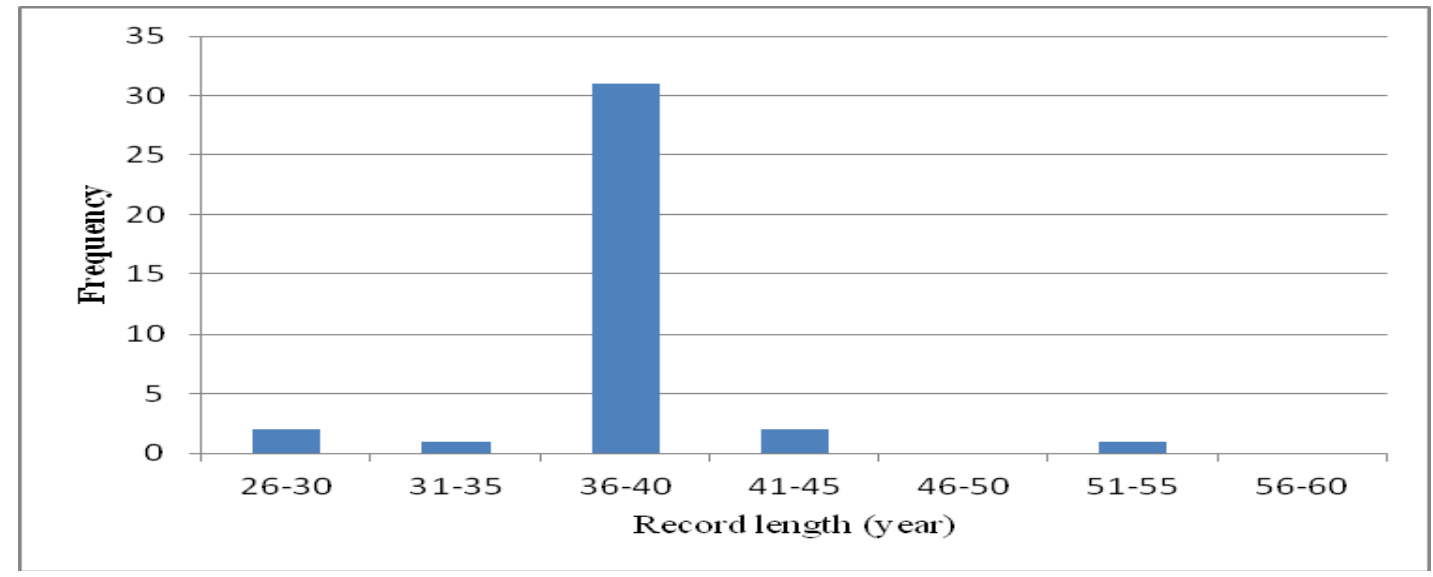

Figure 3. Distribution of record lengths of the 39 stations showing trend at $5 \%$ level of significance.

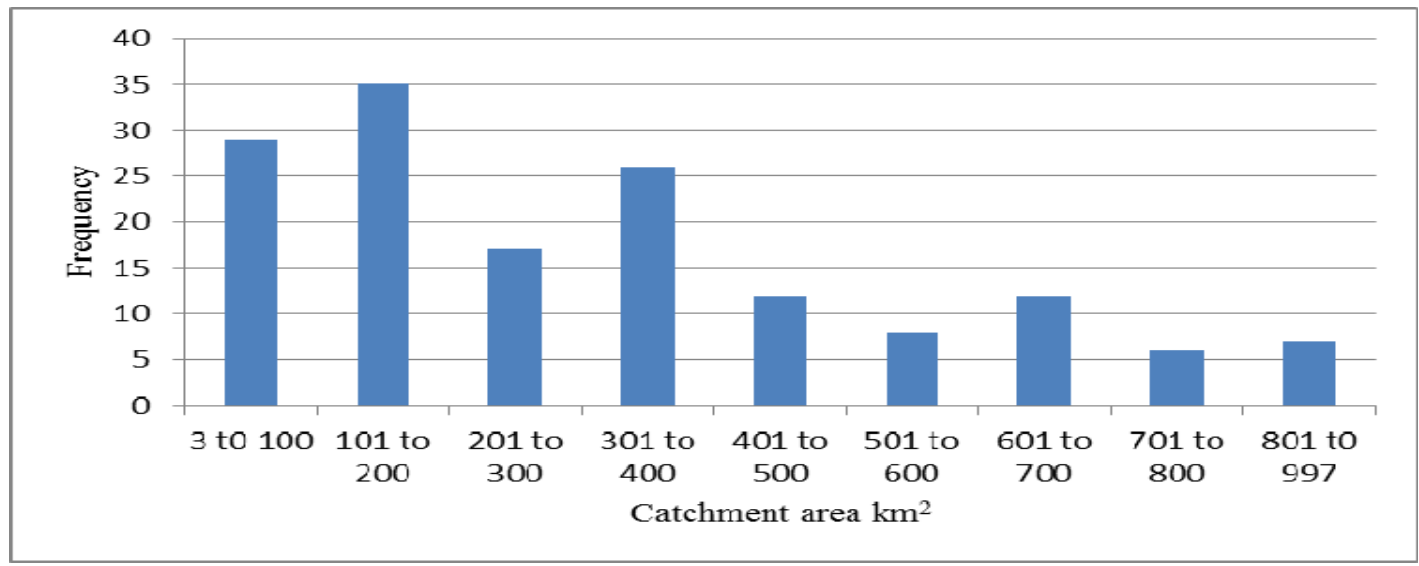

Figure 4. Distribution of catchment areas of all the selected 152 catchments.

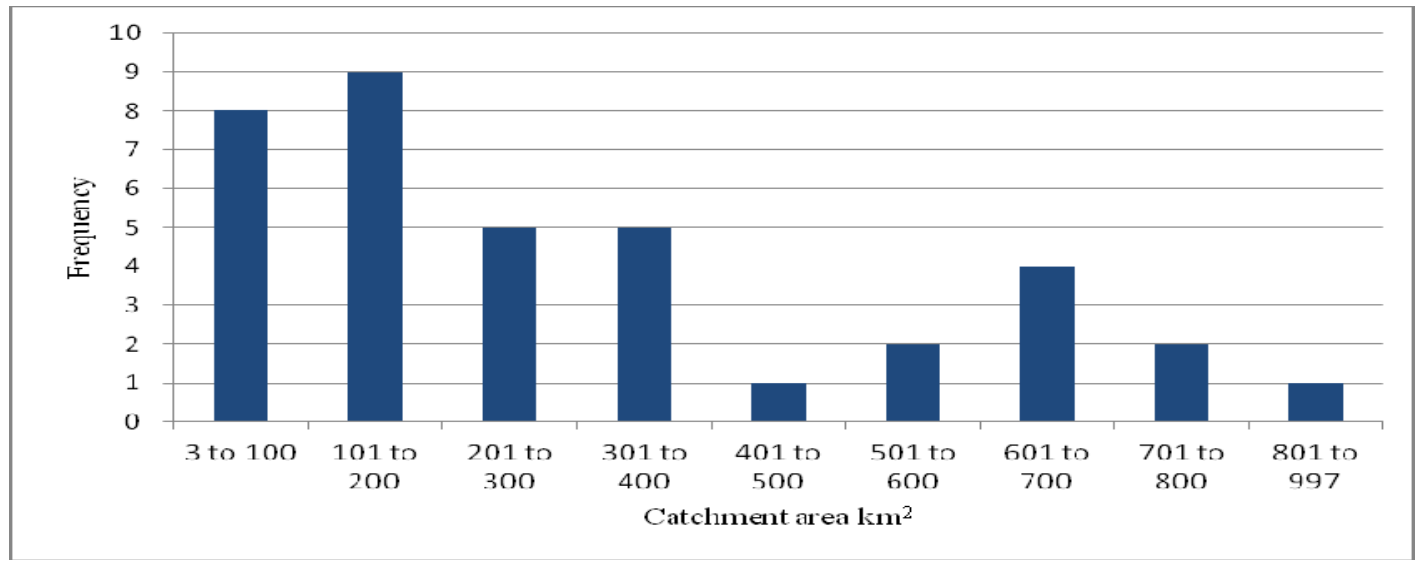

Figure 5. Distribution of catchment areas of the 39 stations showing trend at $5 \%$ level of significance.

\section{RESULTS}

Among 152 catchments examined here, 39 have showed downward trends at $5 \%$ level of significance. This is about $25 \%$ of the total stations showing downward trend. No station has showed upward trend. Table 1 shows some example stations showing trends. The negative value of $Z_{0}$ statistic of Mann-Kendall test refers to the decreasing trend whereas positive value indicates an increasing trend. 
Hossain et al., Trend analysis of flood data in Australia: A case study for Victoria

Table 1. Results of trend test for some example catchments: Negative values indicate downward trend

\begin{tabular}{|c|c|c|c|c|c|}
\hline Stations ID & $\mathbf{Z}_{\mathbf{0}}$-value & Stations ID & $\mathbf{Z}_{\mathbf{0}}$-value & Stations ID & $\mathbf{Z}_{\mathbf{0}}$-value \\
\hline 221209 & $\mathbf{- 2 . 2 7}$ & 230206 & $\mathbf{- 4 . 2 1}$ & 405230 & $\mathbf{- 2 . 7 1}$ \\
\hline 226222 & $\mathbf{- 3 . 5 3}$ & 230211 & $\mathbf{- 2 . 1 7}$ & 406200 & $\mathbf{- 2 . 3 4}$ \\
\hline 227219 & $\mathbf{- 2 . 3 0}$ & 231231 & $\mathbf{- 2 . 1 6}$ & 407213 & $\mathbf{- 2 . 8 4}$ \\
\hline 227227 & $\mathbf{- 2 . 5 2}$ & 231225 & $\mathbf{- 2 . 0 8}$ & 407220 & $\mathbf{- 3 . 9 4}$ \\
\hline 228228 & $\mathbf{- 2 . 2 3}$ & 232210 & $\mathbf{- 2 . 3 0}$ & 407227 & $\mathbf{- 3 . 3 9}$ \\
\hline 230205 & $\mathbf{- 2 . 3 4}$ & 232213 & $\mathbf{- 2 . 6 7}$ & 408202 & $\mathbf{- 2 . 6 0}$ \\
\hline
\end{tabular}
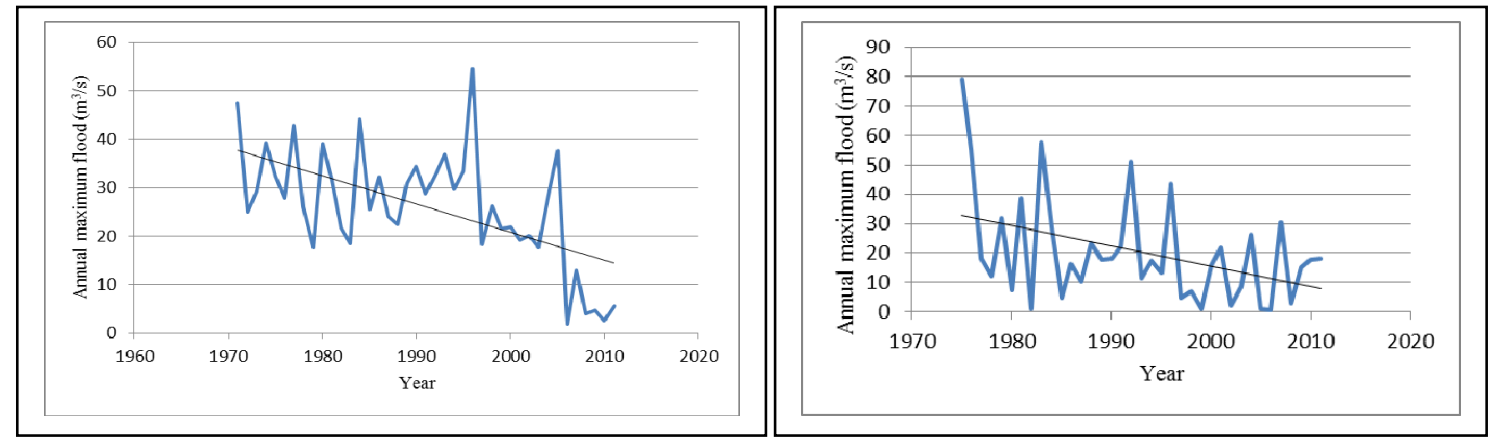

Figure 6. Two example catchments (226222 and 230205, respectively): showing downward trends.

Figure 1 shows the catchments showing trends (where empty and bold diamonds are representing the stations showing no trend and trend, respectively). It is found that many stations concentrated in the middle and in the southwest regions are showing trends but only two stations in the entire eastern Victorian region show trends. Figure 6 shows the trends of two sample stations indicating a noticeable downward trend. All the trends obtained in this test are negative and no positive trend found in Victoria, which is consistent to the findings by previous studies such as Haddad et al. (2008) and Ishak et al. (2010; 2013).

A close examination of the sites exhibiting trends indicate that the drainage basin 407 have the highest number of stations (i.e. 7) displaying downward trends. Also, for the basins 405, 406, 407 and 408 (all of these are adjacent basins), 13 stations are showing downward trends. The reason behind these trends and their relationship with climate change and climate variability indices are yet to be investigated; this will be reported in future publications.

The distributions of catchment areas of the 39 stations showing trends are presented in Figure 5, which shows that the distributions of catchment areas showing trends are very similar to the distributions of catchments areas of all the catchments (Figure 4). This indicates that there is no noticeable relationship between trends and catchment areas. The distributions of streamflow record lengths of the 39 stations showing trends are shown in Figure 3, which indicates that the distributions of record lengths showing trends are very similar to the distributions of record lengths of all the catchments (Figure 2). Moreover, Figure 3 demonstrates that most of the stations showing trends have record lengths greater than 36 years, which indicates that the trends observed here are not greatly affected by sampling variability due to shorter record lengths.

The trend analysis was repeated for $10 \%$ and $1 \%$ significance levels. Here, 60 stations show trends (i.e. $39 \%$ of the stations) at $10 \%$ level of significance and 14 stations show trends (i.e. $9 \%$ of the stations) at $1 \%$ level of significance. In all cases, the demonstrated trends are much higher than that would have been shown by mere sampling variability, which should have been 15,8 and 2 stations for the $10 \%, 5 \%$ and $1 \%$ levels of significance, respectively. These values are indeed much higher i.e. 60, 39 and 14 stations are showing trends at $10 \%, 5 \%$ and $1 \%$ levels of significance, respectively. 


\section{CONCLUSIONS}

This study investigates any possible trends in the latest compiled annual maximum flood data series in Victoria. This uses data till 2011 from 152 Victorian catchments. A Mann-Kendall trend test is used to identify the trends. It has been found that about $25 \%$ of the catchments showing downward trends at $5 \%$ level of significance and interestingly not a single station shows upward trend. The finding of this study is similar to the previous studies that also found a downward trend in the Victorian annual maximum flood data. The trend analysis was also repeated for $10 \%$ and $1 \%$ significance levels as well. Here, 60 stations show trends (i.e. $39 \%$ of the stations) at $10 \%$ level of significance and 14 stations show trends (i.e. $9 \%$ of the stations) at $1 \%$ level of significance. In all cases, the demonstrated trends are much higher than that would have been shown by mere sampling variability. Furthermore, no noticeable relationship between trends and catchment areas is identified. The reason behind these trends is being examined, and will be reported in future publications.

\section{ACKNOWLEDGEMENTS}

The authors would like to acknowledge Department of Sustainability and Environment (Victoria) for providing the streamflow data used in this study.

\section{REFERENCES}

Haddad, K., Rahman, A. and Weinmann, P.E. (2008). Streamflow data preparation for regional flood frequency analysis: Important Lessons from a case study, Water Down Under, Adelaide, Australia.

Helsel, D.R., \& Hirsch, R.M. (2002). Statistical methods in water resources techniques of water resources investigations. U.S. Geological Survey Paper.

Hendon, H.H., Thompson, D.W.J. and Wheeler, M.C. (2007). Australian rainfall and surface temperature variations associated with the Southern Hemisphere Annular Mode. Journal of Climate 20, 2452-2467.

Ishak, E.H., Rahman, A., Westra, S., Sharma, A. and Kuczera, G. (2010). Preliminary analysis of trends in Australian flood data. World Environment and Water resources Congress, American Society of Civil Engineers (ASCE), USA.

Ishak, E.H., Rahman, A., Westra, S., Sharma, A. and Kuczera, G. (2013). Evaluating the non-stationarity of Australian annual maximum flood. Journal of Hydrology, 294, 134-145.

Kendall, M.G. (1975). Rank correlation measures. Charles Griffin, London.

Khaliq, M.N., Ouarda, T.B.M.J., Gachon, P., Sushama, L. and St-Hilarie, A. (2009). Identification of hydrological trends in the presence of serial and cross correlations: A review of selected methods and their application to annual flow regimes of Canadian rivers. Journal of Hydrology, 368, 117-130.

Mann, H.B. (1945). Non-parametric tests against trend. Econometrica, 13, 245-259.

Murphy, B.F. and Timbal, B. (2008). A review of recent climate variability and climate change in southeastern Australia. International Journal of Climatology, 28, 859-879.

Nicholls, N. (2003). Continued anomalous warming in Australia. Geophysical Research Letters, 30, 1370, DIO:10.1029/2003GL017037.

Power, S., Casey, T., Folland, C., Colman, A. and Mehta, V. (1999). Inter-decadal modulation of the impact of ENSO on Australia. Climate Dynamics, 15, 319-324.

Power, S., Sadler, B. and Nicholls, N. (2005). The influence of climate science on water management in Western Australia: Lessons for climate scientists. Bulletin of the American Meteorological Society, 86, 839-844.

Rahman, A., Haddad, K., Zaman, M., Ishak, E., Kuczera, G. and Weinmann, E. (2012). Australian Rainfall and Runoff Revision Project 5: regional flood Method, Stage 2 Report.

Stern, H., Moodie, N., Cornall-Reilly, J., Forster, T. and McBride, P. (2005). Comment on A long-term trend in Melbourne rainfall. Bulletin of American Meteorological and Oceanographic Society, 18, 39-40.

Whetten, P. (1988). A synoptic climatology analysis of rainfall variability in south-eastern Australia. International Journal of Climatology, 8, 155-177. 